11 | 2007

Varia

\title{
Église Saint-Martin de Branches (Yonne)
}

\section{Christian Sapin et Sylvain Aumard}

\section{(2) OpenEdition}

\section{Journals}

\section{Édition électronique}

URL : https://journals.openedition.org/cem/1942

DOI : $10.4000 /$ cem. 1942

ISSN : 1954-3093

Éditeur

Centre d'études médiévales Saint-Germain d'Auxerre

Édition imprimée

Date de publication : 15 août 2007

ISSN : 1623-5770

\section{Référence électronique}

Christian Sapin et Sylvain Aumard, «Église Saint-Martin de Branches (Yonne) », Bulletin du centre d'études médiévales d'Auxerre | BUCEMA [En ligne], 11 | 2007, mis en ligne le 28 août 2007, consulté le 22 septembre 2022. URL : http://journals.openedition.org/cem/1942 ; DOI : https://doi.org/10.4000/ cem. 1942

Ce document a été généré automatiquement le 22 septembre 2022.

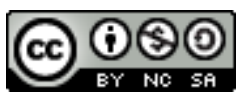

Creative Commons - Attribution - Pas d'Utilisation Commerciale - Partage dans les Mêmes Conditions 4.0 International - CC BY-NC-SA 4.0

https://creativecommons.org/licenses/by-nc-sa/4.0/ 


\title{
Église Saint-Martin de Branches (Yonne)
}

\author{
Christian Sapin et Sylvain Aumard
}

1 Après plusieurs campagnes de relevé du bâti réalisées dans le cadre de stage, ayant permis l'établissement d'un plan et une meilleure connaissance des peintures et des élévations gothiques, nous avons choisi en 2006, en plus des maçonneries, d'analyser et de relever la charpente présentant des caractéristiques propres au XIII ${ }^{\mathrm{e}}$ siècle ainsi que des restes de lambris avec des traces de peinture, éléments rarement conservés pour une date haute. Cette campagne a été accompagnée de sondages au sol permettant de préciser certaines hypothèses de restitution des premiers états de l'édifice. Rappelons que le site est mentionné parmi les possessions de l'évêque Didier au début du VII ${ }^{\mathrm{e}}$ siècle mais que l'on ignore son évolution avant de nouvelles mentions de possessions épiscopales en 1208. En étudiant le mur extérieur nord en opus spicatum, nous avions proposé d'y voir un caractère de construction typique du $\mathrm{XI}^{\mathrm{e}}$ siècle. Le sondage extérieur a confirmé son ancienneté par l'analyse des mortiers et montré sa reprise en sous-œuvre au XIII siècle; à l'intérieur, certains éléments de mortier pourraient appartenir à une banquette primitive s'appuyant à l'est contre l'épaulement dont la maçonnerie est bien cohérente avec la partie nord en opus spicatum. Ces maçonneries, renvoyant à l'état le plus ancien en élévation, s'installent dans des terres contenant des ossements humains erratiques, premier indice d'une occupation funéraire antérieure à l'an mil.

2 Le relevé du bâti plus à l'est de l'épaulement, a confirmé l'existence de deux états d'un passage conduisant $\mathrm{du}$ sanctuaire vers le prieuré au nord; ceci lors des agrandissements gothiques du chevet.

Étude des combles, par Sylvain Aumard

3 Une partie du stage organisé en avril 2006 comportait comme originalité un volet consacré à l'étude des charpentes. Celles-ci supportaient une voûte lambrissée, complètement remplacée aujourd'hui; dans les combles, quelques vestiges exceptionnellement bien conservés de cet ouvrage montrent un décor peint de qualité avec des motifs floraux noirs et rouges. Ces charpentes possèdent l'intérêt d'avoir subi 
peu de transformation depuis leurs origines que plusieurs indices autorisent à placer au début du XIII ${ }^{e}$ siècle : absence de contreventement longitudinal, présence majoritaire d'assemblages à mi-bois à ergots et marquage des bois avec le système à bâtons. Cette datation est en accord avec celles des élévations sous jacentes recouvertes de peintures murales.

Le stage a consisté à amorcer le relevé en plan des entraits visibles dans le chœur et la nef et à étudier le marquage des fermes et leur mise en œuvre. Ce dernier aspect a été réservé à l'espace du chœur où la chronologie s'est avérée un peu plus complexe que prévu. Sa moitié occidentale paraît en effet avoir été refaite au cours de l'époque moderne avec des morceaux de pans bois. Le bas-côté, s'il est de conception proche des éléments attribués au début du XIII ${ }^{\mathrm{e}}$ siècle, possède des indices indiquant une mise en place un peu plus tardive: présence d'un contreventement, absence d'assemblages à mi-bois, marquage avec chiffres romains. D'après les peintures murales, cette partie n'a pu être réalisée après le milieu du XIII ${ }^{e}$ siècle.

5 Les résultats apportés indiquent l'intérêt de poursuivre cette démarche sur le reste du comble et d'envisager des datations par dendrochronologie ${ }^{1}$.

6 Le relevé des peintures s'est poursuivi en présence de Laurence Blondaux (restauratrice). La procession originelle du mur sud se prolonge vers l'est. Sur le mur nord, les différents états du décor autour des croix de consécrations se précisent. Le premier décor correspond à un faux appareil et fleurettes noires (fleurettes rouges à l'origine après oxydation du pigment), à la bande décorative supérieure et aux premiers médaillons avec les apôtres formant une croix de consécration. Cet ensemble $\mathrm{du} \mathrm{XIII}^{\mathrm{e}}$ siècle contemporain de la scène de procession du mur sud et des lambris décorés est repris (fin du siècle ou suivant) par d'autres médaillon d'apôtres, un fond ocre jaune et une résille ocre-rouge foncés, filets blancs. Les reprises suivantes seraient du XVI ${ }^{e}$ siècle (scène de saint Hubert), des XVII ${ }^{e}$ XVIII ${ }^{e}$ siècles (décor de faux marbre et de faux bois notamment).

7 En conclusion, à la vue de l'ensemble des premières données et de leurs croisements, il est désormais possible d'admettre l'existence d'un premier état antérieur au XIII ${ }^{\mathrm{e}}$ siècle constitué d'une nef unique avec un chevet plat plus étroit, puis après 1200 des agrandissements progressifs vers l'est, vers le sud, et enfin seulement au XVIII ${ }^{\mathrm{e}}$ vers l'ouest avec le clocher. Au-delà de ces aspects chronologiques, ces recherches soulignent la volonté de changements importants de l'espace et de son utilisation au XIII ${ }^{e}$ siècle avec probablement la présence à la fois de la prieurale et de la paroisse réduite à une des deux nefs. En inversant les a priori d'une simple connaissance par l'histoire de l'art, réduisant ce type d'édifice à des catégories de second intérêt, l'archéologie dégage progressivement les aspects innovants des constructeurs répondant à des demandes de la société médiévale en mutation.

Enfin, ces travaux et hypothèses qu'il conviendra de poursuivre, contribuent à mieux définir un cahier des charges pour sa restauration. 


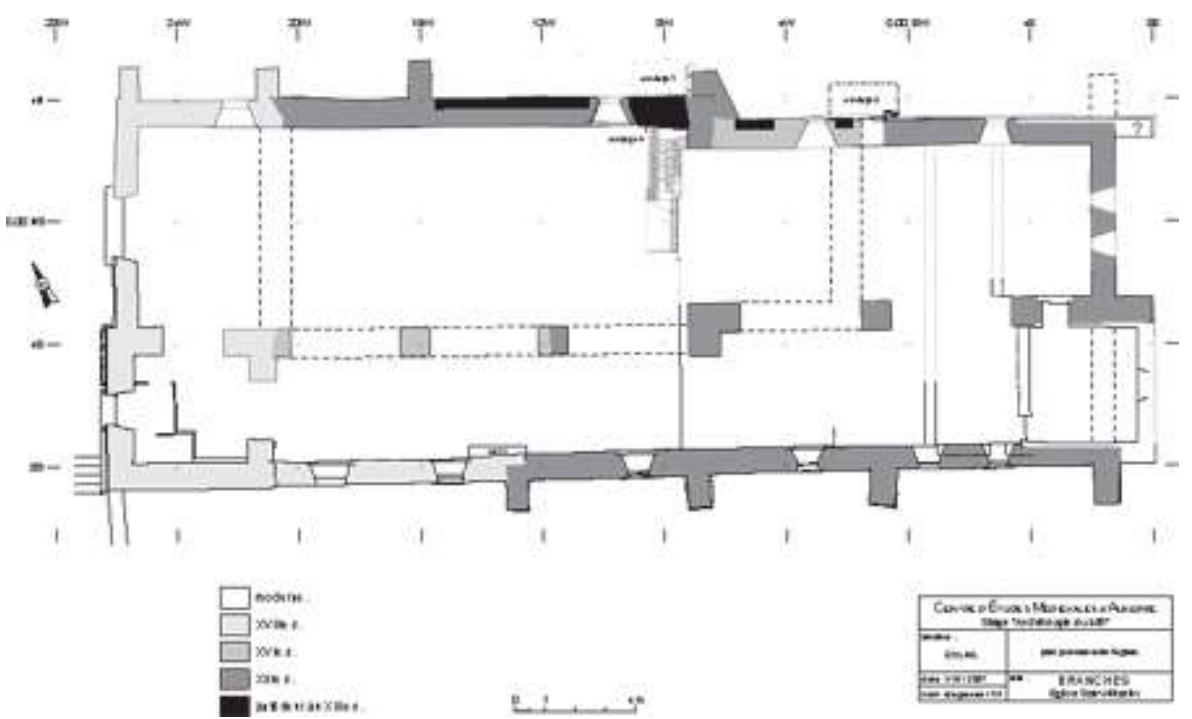

Fig. 1. Branches, église Saint-Martin, plan (dessin G. Fèvre).

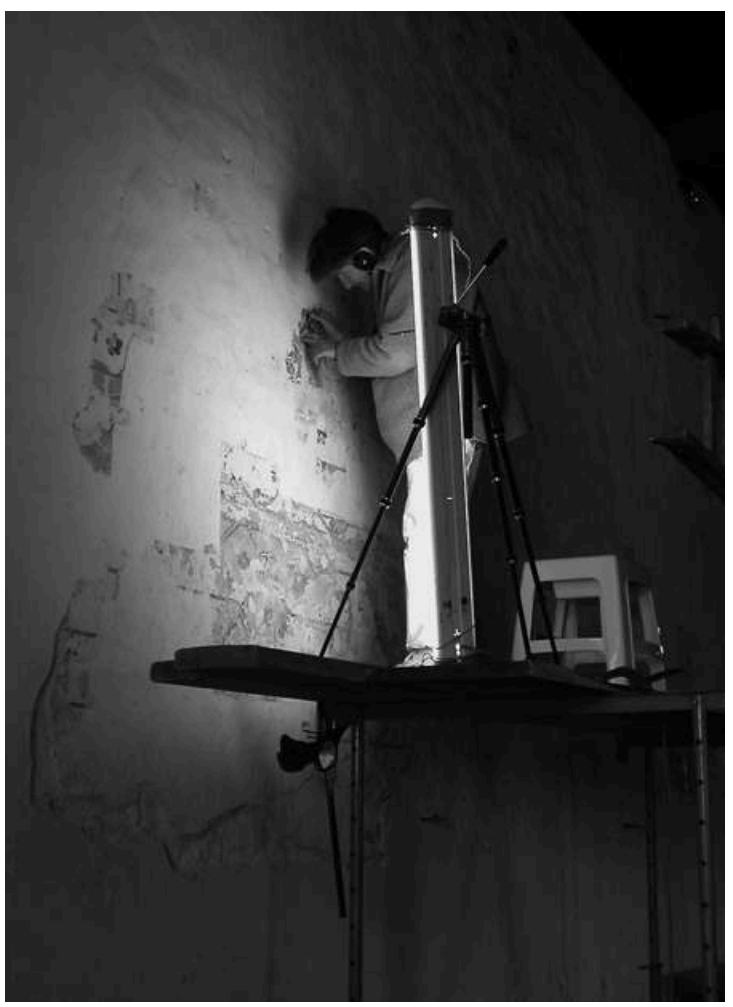

Fig. 2. Branches, église Saint-Martin, relevé des peintures murales par L. Blondaux (cliché CEM) 


\section{NOTES}

1. Au moment où ce bulletin est sous presse, la réalisation de ces analyses est projetée dans le cadre du projet sur les Toits de l'Europe piloté par l'Université de Liège et auquel participe le Centre d'études médiévales d'Auxerre.

INDEX

Mots-clés : charpente, église, peinture, Saint-Martin de Branches

Index géographique : France/Branches 